\title{
REVIEW
}

\section{Errata: Hyperinsulinemia: A unifying theory of chronic disease?}

\author{
Catherine A.P Crofts*1, Caryn Zinn', Mark C Wheldon², Grant M Schofield ${ }^{1}$
}

\begin{abstract}
Errata: The original article was published with an error of hyperinsulinemia improves fibrinolysis, instead hyperinsulinemia impairs fibrinolysis. The error has been corrected in this version.

Globally, there is an increasing prevalence of non-communicable diseases. The morbidity and mortality from these conditions confer a greater economic societal burden. Epidemiological research associates insulin resistance in the etiology of these diseases, but there is limited evidence for the mechanism of damage. Emerging research suggests that hyperinsulinemia, a symptom of insulin resistance, may cause these pathological changes, and therefore be an independent contributor to these diseases. This review shows that hyperinsulinemia, or excessive insulin secretion, should be considered independently to insulin resistance, defined as glucose uptake rate, even though the two conditions are intertwined and will co-exist under normal conditions. Hyperinsulinemia directly and indirectly contributes to a vast array of metabolic diseases including all inflammatory conditions, all vascular diseases, gestational and type 2 diabetes, non-alcoholic fatty liver disease, obesity and certain cancers and dementias. The mechanisms include increased production of: insulin growth factor-1; reactive oxidative species and advanced glycation end-products; and triglyceride and fatty acids. Hyperinsulinemia also directly and indirectly affects many other hormones and cytokine mechanisms including leptin, adiponectin and estrogen. There is limited research standardizing the hyperinsulinemia diagnostic process. Methodological concerns and lack of standardized reference ranges preclude the use of fasting insulin. Most research has also focused on insulin resistance and it is unknown whether these methods translate to hyperinsulinemia.
\end{abstract}

Keywords: Hyperinsulinemia, hyperglycemia, type 2 diabetes, insulin resistance, secretagogue, syndrome $x$

Originally published in Diabesity 2015; 1 (4): 34-43 doi: $\underline{10.15562 / \text { diabesity.2015.19 }}$

\section{Introduction}

Impaired insulin homeostasis encompasses both hyperinsulinemia and hypoinsulinemia. Although the latter is well recognised as type 1 diabetes, there is little literature on the former, despite being first hypothesised in the early 1920s. ${ }^{1}$ Currently, a close approximation to hyperinsulinemia research is that conducted on insulin resistance. Insulin resistance is well-established as underpinning many significant chronic health conditions including type 2 diabetes, metabolic syndrome, cardiovascular disease, some cancers and Alzheimer's disease. ${ }^{2-5}$ This insulin resistance is invariably accompanied by increased demands for insulin so that the body can maintain euglycemia. Excess insulin, termed hyperinsulinemia, may be endogenous from bodily compensation, or exogenous via modern medicine. In this paper we contend that hyperinsulinemia, in concert with insulin resistance, should be considered as an important independent health risk. We exclude isolated hyperinsulinemia, such as that caused by an insulinoma.
It is well recognised that earliest detection of any disease state allows for the best possible outcomes. It is agreed that hyperinsulinemia precedes hyperglycemia, by up to 24 years. 3, 4, 6 There is a strong argument that hyperglycemia indicates pancreatic $\beta$ cell attrition; essentially end-stage organ damage. $3,7 \mathrm{We}$ contend that the under-recognition of hyperinsulinemia is an important clinical issue because there are no standard diagnostic reference values, is most accurately diagnosed with dynamic glucose and insulin testing, and has few (pharmaceutical) management options. This review will discuss pathophysiology and diagnosis of hyperinsulinemia.

Hyperinsulinemia was first theorised in $1924{ }^{1}$, but it was not until the 1960's that direct insulin measurements became possible. ${ }^{8}$ Since then, there has been a wealth of research in the field of insulin resistance with a small amount of research into hyperinsulinemia. Therefore, we highlight the disease states that are both directly and/or indirectly 
associated with hyperinsulinemia. We also discuss the availability and limitations of current diagnostic methods for hyperinsulinemia and why further investigations are needed.

\section{Methodology}

For this narrative review, literature was reviewed on hyperinsulinemia and insulin resistance, targeting fulltext English language studies. There was no date criterion. Articles were selected on the basis of having a minimum of both a plausible biological mechanism and established clinical association. Initially, the academic database search included EBSCO, Medline and Google Scholar, using variants of the terms 'hyperinsulinemia', 'insulin resistance', 'metabolic syndrome', and 'syndrome $\mathrm{x}$ ', individually and conjunction with 'non-communicable disease', 'mechanism', 'atherosclerosis', and 'cardiovascular disease'. As subsequent metabolic diseases and/or mechanisms were eluded to in the initial search, search terms were widened so that no disease state was excluded. Subsequent metabolic diseases included, but were not limited to, conditions such as 'non-alcoholic fatty liver disease', 'cancer', 'dementia'. The final selection of references was based on the authors' judgment of relevance, completeness, and compatibility with clinical, epidemiological, pathological and biochemical criteria.

\section{Hyperinsulinemia}

\section{Definition}

There is no precise definition of hyperinsulinemia. It is often described as 'more insulin than normal to achieve euglycemia'; essentially the same as insulin resistance. Where a reference range is available, it is normally based on fasting levels and include $5-13 \mu \mathrm{U} / \mathrm{mL}^{9}, \leq 30 \mu \mathrm{U} / \mathrm{mL}^{10}$, and $18-173$ $\mathrm{pmol} / \mathrm{L}(3-28 \mu \mathrm{U} / \mathrm{mL})^{11}$ However, there are very few studies where a 'normal level of insulin' is defined as many studies define hyperinsulinemia based on quantiles. ${ }^{12-14}$ Few studies have been more specific. Both a fasting serum insulin of $\geq 12.2 \mu \mathrm{U} / \mathrm{mL}$ in the presence of euglycemia ${ }^{15}$ and a range of $8-11 \mu \mathrm{U} / \mathrm{mL}$ 'between meals' and up to $60 \mu \mathrm{U} / \mathrm{mL}$ 'after meals' 16 have been proposed. There are also practical, methodological issues with determining insulin resistance under the World Health Organization (WHO) conditions that will be discussed later in this review.

\section{Etiology}

Diabesity 2015; 1(4): 34-43. doi: 10.15562/diabesity.2015.19
The etiology of hyperinsulinemia is not yet fully elucidated. Although there are several theories, further research will likely show a multimodal pathology. What can be deduced from physiological principles is:

1. Healthy cells are subjected to acute hyperglycemia. 2. Although many cells can absorb glucose without using insulin (GLUT1 transportation) hyperglycemia causes insulin to be released from pancreatic cells to facilitate absorption, especially in muscle and adipose cells (GLUT 4 transportation). ${ }^{17}$ 3. Insulin binds to cellular insulin receptors and facilitates translocation of GLUT4 to the cellular surface. During this process the insulin and its receptor are absorbed into the cell to be replaced from the internal pool of insulin receptors. ${ }^{18}$ 4. This acute insulin resistance is of no consequence as long as the cell has viable GLUT4 on the cellular surface. However, GLUT4 have a relatively short halflife. ${ }^{19}$ 5. If hyperglycemia persists, the pancreas maintains insulin secretion. This may deplete the insulin receptors faster than they can be replaced. 6 . During this period where the cells are replacing their insulin receptors, moderately elevated blood glucose levels, (such as that immediately found after a normal meal) may need slightly higher than normal insulin levels to restore normoglycemia. This moderate hyperinsulinemia may delay the return to normal insulin receptor function (acute insulin resistance). ${ }^{7}$ This state of insulin resistance due to down-regulated insulin receptors is reversible should the person not be subjected to further episodes of hyperglycemia. It does not matter whether this is via high, but acute, blood glucose elevations, or moderately elevated glucose levels over a prolonged period. 8. Prolonged impaired insulin signaling impedes GLUT4 translocation to the cellular surface thus causing impaired glucose uptake and prolonging hyperglycemia, causing a positive feedback cycle. This will both aggravate and prolong the insulin resistance, potentially turning it from a transitory state to a persistent or chronic state.

The complexity of the insulin receptor regulation, combined with the availability of GLUT4 and factors that influence insulin secretion mean that it is impossible to generalize whether insulin resistance precedes or follows hyperinsulinemia. It is more plausible that different individuals have different triggers in the cycle. These triggers may include genetic factors, excessive carbohydrate, corticosteroids (endogenous or exogenous), free fatty acids, leptin, or certain medications; each of these are discussed below.

Fructose: Fructose is metabolized in liver into ATP and/or triglycerides in a process that is competitive with, and preferential to, glucose. If excessive fructose 
is consumed, glucose will not be metabolized causing hyperglycemia and subsequent hyperinsulinemia. ${ }^{20,21}$ Excessive fructose also results in hyperuricemia which is associated with reduced endothelial nitric oxide causing vasoconstriction, endothelial dysfunction and insulin resistance. ${ }^{21}$

Hyperglycemia: Hyperglycemia alone can aggravate insulin resistance..$^{22}$ Along with excessive carbohydrate ingestion, other mechanisms for this mechanism include hepatic insulin resistance. Increased plasma insulin slows hepatic gluconeogenesis but this process can be impaired by hepatic insulin resistance leading to peripheral hyperglycemia and further insulin secretion. ${ }^{23}$

Corticosteroids: It is known that corticosteroids, especially endogenous cortisol, cause a down regulation of GLUT-4 receptors, thus preventing glucose uptake and provoking hyperinsulinemia in the presence of hyperglycemia. Long-term courses of exogenous corticosteroids, such as prednisone, are known to cause 'drug-induced' type 2 diabetes, which may resolve after the medication is discontinued. Not every patient on long-term corticosteroids will develop drug-induced diabetes. Therefore, it is plausible that the patient's degree of insulin resistance at baseline influences disease development/progression. Given that stress causes a temporary rise in cortisol levels, it is also plausible that prolonged stress may be another cause of hyperinsulinemia. ${ }^{24}$

Leptin: Appetite control is mediated from the hypothalamus in response to a balance between leptin and insulin controlling neuropeptide $\mathrm{Y}$ expression. ${ }^{25}$ This balance is believed important to manage caloric intake over longer periods of time when meals can vary in size, frequency and composition. Leptin secretion is slow to change as it is influenced by total body fat mass and total caloric intake, while insulin secretion is highly responsive to food ingestion and will change quickly with every meal. Leptin is also highly influenced by insulin as it is released from fat stores by mechanisms that appear to involve glucose flux. ${ }^{25}$ Experimental evidence shows that reducing insulin secretion reduces leptin resistance, suggesting a relationship between hyperinsulinemia and hyperleptinemia. ${ }^{26}$ It is not yet clear whether hyperleptinemia is causative of hyperinsulinemia beyond the association of obesity and an increase in free fatty acids.

Medication-induced: There are a number of medications known or suspected to cause hyperinsulinemia and/or contribute to insulin resistance. Exogenous corticosteroids (prednisone) and exogenous insulin and insulin secretagogues (sulphonylureas) have had their mechanisms discussed. Other medications include the antipsychotics (e.g. clozapine), and statins. $^{27}$ The mechanisms for these medications causing hyperinsulinemia are currently unknown.

Due to the nature of insulin receptor regulation, it is also plausible that insulin sensitivity of the cells can be restored. This would require the absence of both hyperinsulinemia and hyperglycemia. Case studies indicate that a carbohydrate restricted diet may facilitate this effect. ${ }^{10}$

Overall, it should be recognized that hyperinsulinemia is independent to insulin resistance: Hyperinsulinemia is excessive insulin secretion, while insulin resistance is impaired glucose uptake. This review investigates the both the mechanistic and epidemiological evidence that links hyperinsulinemia to metabolic disease. Although there is good quality research mechanistically linking hyperinsulinemia to subsequent pathologies, there is a paucity of good epidemiological evidence. Given the intertwined nature between insulin resistance and hyperinsulinemia as depicted above, it can be assumed that the majority of people with insulin resistance are also hyperinsulinemic. Therefore, if no epidemiological data was available, this review used epidemiological research based on insulin resistance as a proxy for hyperinsulinemia.

\section{Direct effects of hyperinsulinemia}

As shown in Table 1, hyperinsulinemia can be mechanistically and epidemiologically linked to metabolic syndrome, gestational and type 2 diabetes and therefore, cardiovascular and other diseases with an increased prevalence in those with metabolic syndrome. ${ }^{2-4,28}$ It is also an independent risk factor for a number of other diverse conditions including dietinduced obesity, osteoarthritis, certain cancers, especially breast and colon/rectum, and Alzheimer's disease and other dementias.5, 6, 29-32

Other conditions that may be associated with hyperinsulinemia, via either epidemiological evidence or potential mechanism of action, include gout, tinnitus, schizophrenia and autism. ${ }^{33-36}$ Further research is needed to confirm these associations.

\section{Pathophysiological mechanisms}

Hyperinsulinemia affects the body via five main mechanisms: Increased reactive oxidative species and advanced glycation end-products; increased insulin-like growth factor-1 (IGF-1); hyperglycemia; increased fatty acid/triglyceride production; and by affecting different hormones and cytokines.

\section{Reactive oxidative species}


Reactive oxygen species is a collective term that includes both oxygen radicals and non-radical 
Table 1. Biological systems and disease states affected by hyperinsulinemia, and associated mechanisms of action

\begin{tabular}{|c|c|c|c|c|c|}
\hline \multirow{2}{*}{$\begin{array}{l}\text { Biological } \\
\text { System }\end{array}$} & \multirow{2}{*}{ Disease } & \multirow{2}{*}{ Mechanism } & \multirow{2}{*}{$\begin{array}{l}\text { Direct or } \\
\text { indirect } \\
\text { mechanism }\end{array}$} & \multicolumn{2}{|c|}{ References } \\
\hline & & & & $\begin{array}{l}\text { Mechanism } \\
\text { of action }\end{array}$ & Epidemiology \\
\hline \multirow{4}{*}{ Cancer* } & \multirow{4}{*}{$\begin{array}{l}\text { Cancer } \\
\text { (Breast, ovarian, colon, } \\
\text { bladder, pancreas \& } \\
\text { liver) }\end{array}$} & $\begin{array}{l}\text { Increased insulin-like growth factor IGF-1 enhances cellular } \\
\text { growth and proliferation. }\end{array}$ & Direct & $(5,48)$ & $(29)$ \\
\hline & & $\begin{array}{l}\text { Enhanced glucose uptake and utilization enhances cellular } \\
\text { growth and proliferation. }\end{array}$ & Both & (29) & (29) \\
\hline & & $\begin{array}{l}\text { Increased production of reactive oxidative species causes } \\
\text { derangement of DNA and enzymes involved with repair } \\
\text { mechanisms (enhanced by hyperglycemia). }\end{array}$ & Indirect & $(2,37,38)$ & $(2,37,38)$ \\
\hline & & $\begin{array}{l}\text { Increased sex-hormone production and decreased sex } \\
\text { hormone binding globulin causes increased cellular growth } \\
\text { and proliferation (enhanced by obesity). }\end{array}$ & Direct & (29) & (29) \\
\hline \multirow{7}{*}{ Circulatory } & Atherosclerosis & $\begin{array}{l}\text { Arterial wall damage caused by inflammation, increased } \\
\text { proliferation and migration of arterial smooth muscle cells. } \\
\text { Stimulation of the mitogen-activated protein kinase pathway. }\end{array}$ & Both & $(28,40)$ & $\begin{array}{c}(28,47,63, \\
64)\end{array}$ \\
\hline & & $\begin{array}{l}\text { Microvascular disease, including changes to capillary } \\
\text { permeability, microaneurysm formation, vasoconstriction and } \\
\text { microthrombi. }\end{array}$ & & & \\
\hline & Cardiomyopathy & $\begin{array}{l}\text { Increased myocardial fibrosis by increased reactive } \\
\text { oxidative species, deranged collagen production. }\end{array}$ & Both & $(65,66)$ & $(65,66)$ \\
\hline & \multirow{3}{*}{ Endothelial dysfunction } & \multicolumn{2}{|l|}{$\begin{array}{l}\text { Diabetic neuropathy causes changes to catecholamines, which } \\
\text { further impairs myocardial function. }\end{array}$} & & \\
\hline & & $\begin{array}{l}\text { Vasoconstriction and pro-atherosclerotic effects from } \\
\text { decreased nitric oxide bioavailability and action and } \\
\text { increased thromboxane. }\end{array}$ & Both & $(2,41,67)$ & (64) \\
\hline & & $\begin{array}{l}\text { Enhanced by increased reactive oxidative species and } \\
\text { advanced glycation end-products. }\end{array}$ & & & \\
\hline & Thrombosis & $\begin{array}{l}\text { Hyperinsulinemia causes impaired fibrinolysis while } \\
\text { hyperglycemia causes increased blood coagulability }\end{array}$ & Indirect & (42) & (64) \\
\hline \multirow{4}{*}{ Gastrointestinal } & Diabetes: Gestational & $\begin{array}{l}\text { Pre-existing insulin resistance and increased demand for } \\
\text { insulin. }\end{array}$ & Direct & (68) & (68) \\
\hline & $\begin{array}{l}\text { Diabetes: } \\
\text { Type } 2\end{array}$ & $\begin{array}{l}\text { Prolonged insulin resistance eventuating in beta-cell failure. } \\
\text { Down-regulation of glucose transporter- } 4 \text {. }\end{array}$ & Direct & $(3,69,70)$ & (4) \\
\hline & Hyper- triglyceridemia & Increased triglyceride production. & Direct & $(43,71)$ & $(72)$ \\
\hline & $\begin{array}{l}\text { Non-alcoholic fatty } \\
\text { liver disease }\end{array}$ & $\begin{array}{l}\text { Fatty acid production exceeds distribution capacity. } \\
\text { Aggravated by inflammation and oxidative stress. }\end{array}$ & Direct & (71) & $(72)$ \\
\hline \multirow[t]{3}{*}{ Endocrine } & Chronic inflammation & $\begin{array}{l}\text { Stimulation of mitogen-activated protein kinase pathway; } \\
\text { glycemic variability; hyperglycemia and/or obesity } \\
\text { influences increased cytokine production. }\end{array}$ & Indirect & $(40,48)$ & $(73)$ \\
\hline & Obesity & Decreased lipolysis. & Direct & (74) & (75) \\
\hline & & Lack of appetite suppression. & Direct & $(25,26)$ & (76) \\
\hline \multirow[t]{2}{*}{ Nervous } & \multirow[t]{2}{*}{$\begin{array}{l}\text { Alzheimer's disease } \\
\text { and vascular dementia }\end{array}$} & $\begin{array}{l}\text { Endothelial dysfunction resulting in microvascular disease, } \\
\text { metabolic disturbances and neuronal damage. }\end{array}$ & Direct & $(2,67,77)$ & $(30,78,79)$ \\
\hline & & $\begin{array}{l}\text { Impaired blood coagulability and/or fibrinolysis cause } \\
\text { multiple thrombotic events. }\end{array}$ & Both & $(42,80)$ & \\
\hline \multicolumn{4}{|c|}{ Diabesity 2015; 1(4): 34-43. doi: 10.15562/diabesity.2015.19 } & www.diabesi & $\frac{\text { ejournals.ca }}{3 \varepsilon}$ \\
\hline
\end{tabular}




\begin{tabular}{|c|c|c|c|c|c|}
\hline & & $\begin{array}{l}\text { Changed regulation of beta-amyloid and tau protein } \\
\text { (Alzheimer's disease). }\end{array}$ & Direct & $(77,81)$ & \\
\hline & \multirow{3}{*}{ Peripheral neuropathy } & $\begin{array}{l}\text { Decreased synaptic plasticity caused by dysregulated PSA- } \\
\text { NCAM interactions (Alzheimer's disease). }\end{array}$ & Direct & (33) & \multirow{3}{*}{$(64,82)$} \\
\hline & & $\begin{array}{l}\text { Increased production of reactive oxidative species and } \\
\text { advanced glycation end-products enhanced by } \\
\text { hyperglycemia. }\end{array}$ & Indirect & $(2,41)$ & \\
\hline & & Insulin resistance in the dorsal root ganglion neurons. & Both & (83) & \\
\hline & Retinopathy & $\begin{array}{l}\text { Hyperglycemia and endothelial dysfunction contribute blood- } \\
\text { retinal barrier breakdown. Aggravated by excess advanced } \\
\text { glycation end-products. }\end{array}$ & Direct & $(41,64,84)$ & $(41,64,84)$ \\
\hline Skeletal & Osteoporosis & $\begin{array}{l}\text { Increased reactive oxidative species and/hyperglycemia } \\
\text { cause collagen breakdown, impairs new collagen synthesis } \\
\text { and compromises mensenchymal cells. }\end{array}$ & Indirect & $(31)$ & (31) \\
\hline \multirow[t]{2}{*}{ Urinary } & Nephropathy & $\begin{array}{l}\text { Microvascular disease, including changes to capillary } \\
\text { permeability, microaneurysm formation, vasoconstriction and } \\
\text { microthrombi. }\end{array}$ & Direct & $(67,85)$ & \multirow[t]{2}{*}{$(64,86)$} \\
\hline & & $\begin{array}{l}\text { Increased production of reactive oxidative species and } \\
\text { advanced glycation end-products enhanced by } \\
\text { hyperglycemia. }\end{array}$ & Indirect & $(41,87)$ & \\
\hline
\end{tabular}

*While cancer is not typically classified as a "biological system", due to its recognition and impact as a key chronic disease, it was decided that it warrants a classification on its own, rather than be integrated into individual biological systems. PSA-NCAM-polysialic acid - neural cell adhesion molecule.

oxidising agents such as hydrogen peroxide. ${ }^{37}$ Reactive oxidative species are also produced during, and involved in, many metabolic processes including enzymatic reactions, gene expression and signal transduction. ${ }^{37}$ Generally, the actions of intracellular reducing agents such as antioxidants prevent reactive oxidative species-mediated damage. However, a number of factors can contribute to excessive production of reactive oxidative species including excessive calorie consumption and the presence of various pro-inflammatory mediators, including tumor necrosis factor- $\alpha .{ }^{37}$ Once produced, reactive oxidative species can interact with numerous cellular components including DNA, lipids, and amino acids. Damage to DNA is likely to be the underlying mechanism for reactive oxidative species being associated with cancer and early aging. ${ }^{38}$ Polyunsaturated fatty acids are considered very susceptible to reactive oxidative species damage, triggering lipid peroxidation, which can affect cell membrane fluidity and integrity, potentially being the mechanism for endothelial damage. ${ }^{37}$ Amino acids such as cysteine and methionine are very susceptible to reactive oxidative species damage. Changes to these amino acids are implicated in the development of Alzheimer's disease. ${ }^{39}$

Hyperinsulinemia is associated with increased reactive oxidative species, although the exact mechanism is disputed. Hyperinsulinemia is mechanistically linked to excessive serum glucose and free fatty acids. Either substrate can cause increased reactive oxidative species production. ${ }^{2}$ Insulin has also been demonstrated to have some inhibitory effects on reactive oxidative species production that may be independent of its effects on glycemia. ${ }^{40}$ However, reducing insulin-stimulated nutrient uptake into the cell is also believed to decrease reactive oxidative species production. ${ }^{2}$ Further research is required to better understand these mechanisms.

Over-nutrition is also thought to be responsible for the formation of advanced glycation end-products via non-enzymatic glycation and glycooxidation processes. ${ }^{41}$ Defective renal excretion of advanced glycation end-products, as seen with diabetic nephropathy, and consumption of exogenous advanced glycation end-products increases plasma advanced glycation end-product levels. Advanced glycation end-products are believed to contribute to changes in the microvascular systems and also promote changes to inflammatory, oxidative and other degenerative processes of various chronic diseases including neuropathies. ${ }^{41}$

\section{Growth factors (IGF, vascular endothelial growth factor)}

Insulin, IGF-1 and other substances such as vascular endothelial growth factor (VEGF) can stimulate the growth and division of many cells. Insulin can mediate cellular division but may also stimulate cancer cell proliferation and metastasis. ${ }^{29}$ Most importantly, insulin increases the bioavailability of IGF-1, thus insulin is indirectly implicated in all IGF-1 mediated processes. These processes include changes to vascular structures, increases to cellular division and prevention of apoptosis 


\section{Hyperglycemia}

Hyperglycemia commonly follows hyperinsulinemia ${ }^{3}$ but there is little information to suggest whether fasting glucose, peak glucose, or areaunder-the curve (AUC) have the most adverse health impact. Cancer cells have a continuously high glucose uptake, which enhances cellular growth and proliferation ${ }^{29}$; hyperglycemia augments this process. Hyperglycemia allows IGF-1 to stimulate vascular smooth muscle proliferation, which is a hall-mark of both cancer and atherosclerosis. Blood coagulability is also increased by hyperglycemia irrespective of insulin levels. ${ }^{42}$

\section{Increased fatty acid and triglyceride production}

Hyperinsulinemia influences both free fatty acid and triglyceride production. ${ }^{43}$ While the processes that occur during hepatic de novo lipogenesis are not disputed, there is debate as to whether hyperinsulinemia precedes, or are a consequence of fatty liver. ${ }^{44}$ Nevertheless, elevated triglyceride levels are recognized to be a key component of metabolic syndrome (Table 1) while fatty liver may be considered a hepatic manifestation of metabolic syndrome and may progress to cirrhosis or hepatocellular cancer. ${ }^{44}$ Elevated triglyceride levels may also further impair leptin resistance. ${ }^{20,45}$

\section{Hormone/cytokine production (sex hormones, inflammation, obesity)}

Hyperinsulinemia is involved with adiposity via increased appetite and triglyceride production, thereby increasing adiposity. ${ }^{46,47}$ Adipose tissue is now well-established as an endocrine organ and produces both hormones and cytokines that are used for cellular communication. Hypertrophic adipose tissues activate inflammatory and stress pathways and decreases insulin response. This results in increased cytokine production including $\mathrm{TNF}-\alpha$, vascular endothelial growth factor and leptin, while adiponectin expression is decreased. ${ }^{48}$ These actions contribute to decreased glucose and lipid uptake, leading to further reductions to adiponectin secretion and adipogenesis as well as contributing to further insulin resistance. Decreased glucose uptake means there is less glycerol within the adipocyte to esterify free fatty acids, allowing them to infiltrate and accumulate in other tissues.

Adiponectin decreases proliferation of cell types including adipocytes, endothelial cells and cancer cells. ${ }^{48}$ The role of leptin is yet to be fully understood, but it is accepted that hyperinsulinemia and hyperleptinemia results in central leptin resistance, and consequent prevention of appetite suppression and promotion of further obesity. ${ }^{25,} 26,49$ Hyperleptinemia is also linked to increased inflammatory cytokines, changes in nitric oxide, and further endothelial injury. ${ }^{49}$

Hyperinsulinemia is also believed to elevate plasminogen activator inhibitor type-1 (PAL-1) levels, with associated impaired fibrinolysis and increased risk of thrombosis. When combined with the increased coagulation from hyperglycemia, this may explain why over $80 \%$ of people with type 2 diabetes have a thrombotic death. ${ }^{42}$

\section{Diagnosis}

Diagnosing hyperinsulinemia is challenging partly because the health effects of insulin resistance and hyperinsulinemia have been conflated. Further challenges arise when interpreting the available literature. As previously discussed, fasting insulin levels have been assessed as a means of diagnosing hyperinsulinemia with differing results. But it is not just the insulin level alone that is problematic. How and when sampling occurs will also cause variation to results. Insulin levels are higher in serum compared to plasma samples meaning that studies reporting serum insulin cannot be compared directly to plasma insulin. ${ }^{50,51}$ Insulin secretion is pulsatile leading to significant levels in plasma insulin in a short space of time. It is recommended that the mean of three samples taken at five minute intervals be used if a fasting insulin level is required ${ }^{52}$, however this rarely seem to happen in practice. Single fasting insulin samples can have a coefficient of variation of 25$50 \% .53$ This variation decreases testing sensitivity and is perhaps why fasting insulin is not recommended to be used clinically. ${ }^{54}$

It is unknown whether insulin resistance testing can be used to diagnose hyperinsulinemia. The gold standard for measuring insulin resistance is the hyperinsulinemic-euglycemic clamp test. The lowest quartile of glucose uptake rate defines insulin resistance for that study population. Figures for this lower quartile have ranged from $<4.7 \mathrm{mg} / \mathrm{kg} \cdot \mathrm{min}$ to $\leq 6.3 \mathrm{M} \cdot \mathrm{mU}^{-1} \cdot \mathrm{L}^{-1}$, however differences in insulin infusion rates, glucose disposal rate calculations, and background populations under investigation means that there are limits to the generalizability of these results. ${ }^{15,55-58}$ Furthermore, given the complexity of the procedure, the hyperinsulinemic-euglycemic clamp test has little to no clinical application. ${ }^{15}$

A further complication to using the clamp test to assess hyperinsulinemia is that the high dose infusion of insulin will confound any effects of endogenous insulin secretion. As theorized above, the damage associated with hyperinsulinemia is due to the 
continuous action of insulin in the tissues. The amount of insulin normally present in the tissues cannot be measured during the clamp process. It is unknown whether glucose uptake rates correlate with insulin secretion.

A number of tests have been developed that are validated against the hyperinsulinemic-euglycemic clamp that has more clinical applicability. Those based on fasting insulin include homeostatic model assessment (HOMA or HOMA2), McAuley Index, and the quantitative insulin sensitivity check index (QUICKI). ${ }^{15}$, 56, 59 Although HOMA has since been refined to the HOMA2 model, both are modelled on the combination of fasting insulin to fasting glucose. The original HOMA has a $89 \%$ sensitivity and 67\% specificity compared to hyperinsulinemia-euglycemic clamp. ${ }^{57}$ The McAuley index is calculated from fasting insulin and fasting triglyceride levels with 61\% sensitivity and $85 \%$ specificity. ${ }^{15}$

Another insulin resistance test, the oral glucose sensitivity index (OGIS), is modelled on the results derived from an oral glucose tolerance test. ${ }^{56}$ OGIS uses both blood insulin and glucose levels at baseline, $120 \mathrm{~min}$ and $180 \mathrm{~min}$. A spreadsheet is recommended for the calculations (available from http://webmet.pd.cnr.it/ogis/download.php). The OGIS is validated against the hyperinsulinemiceuglycemic clamp assessments for insulin resistance, but as previously stated, the generalizability of clamps is limited.

Both the OGIS and tests based on fasting insulin levels have more clinical applicability for assessing insulin resistance compared to the hyperinsulinemic-euglycemic clamp test. However, insulin resistance testing has never translated to improvements in disease risk calculations. The WHO definition for insulin resistance means that one in four people would be diagnosed with insulin resistance; a figure that may be unrelated to their actual health risks. ${ }^{60}$ Analysis from the Women's Health Initiative Biomarkers study showed that although HOMA-IR had a positive association with cardiovascular risk, this was became non-significant after adjusting for other risk factors such as HDL cholesterol. ${ }^{61}$ There is an argument that HOMA-IR should be used in combination with $\mathrm{HOMA}-\% \mathrm{~B}$ for assessing insulin resistance..$^{52}$

Emerging research now suggests that insulin response patterns following an oral glucose load may determine hyperinsulinemic status. Kraft 7,10 demonstrated the variability of insulin response to a $100 \mathrm{~g}$ glucose load over 3-5 hours, especially with respect to timing and magnitude of the insulin peak and rate of response decline. Five main insulin response patterns are clearly identifiable, with pattern I being considered normal insulin tolerance. From this research Kraft concluded that the most accurate means of assessing hyperinsulinemia was a 3-hour oral glucose tolerance test with insulin levels assessed at baseline, 30, 60, 120, and, at minimum, 180 minutes but 240 and 300 minute insulin levels could also be considered. This study was cross-sectional and there are no long-term outcomes.

Hayashi and colleagues ${ }^{62}$ have shown that the insulinemic pattern produced from sampling every 30 minutes during a 2-hour OGTT can predict the development of type 2 diabetes. An insulin peak delayed beyond 60 minutes being associated with poorer health is common to both Kraft and Hayashi patterns. Further research is required to understand how to apply these patterns to clinical practice.

Collectively these studies show that there is a paucity of research for diagnosing hyperinsulinemia. Most studies focus on insulin resistance testing, but it remains unknown whether insulin resistance correlates with insulin secretion.

\section{Concluding remarks}

This review clearly demonstrates that not only is hyperinsulinemia involved with the etiology of all of the symptoms of metabolic syndrome, it is also implicated in many other conditions; some of which have previously been considered to be idiopathic, such as tinnitus. This raises many questions with both clinical and research implications. Firstly, what is the prevalence of hyperinsulinemia? Given its association with metabolic syndrome and fatty liver disease, this warrants investigation. Could early detection and careful management of hyperinsulinemia decrease the need for medical interventions later in life? Would managing hyperinsulinemia improve to both quantity and quality of life? Yet there are currently too many questions regarding diagnosis. A reliable and repeatable result when sampling insulin is still a challenging task. There is no agreed upon reference range, and there are only associations between quantiles and ongoing disease risk. Insulin response patterning may answer some of these questions, but patterning requires more resources than a fasting level. Given the global concerns about the 'epidemic' of metabolic diseases, this research needs to be urgently addressed.

\section{Conflict of interest}

None Declared. 


\section{References}

1. Harris S. Hyperinsulinism and dysinsulinism. Journal of the American Medical Association. 1924;83:729-33.

2. Ceriello A, Motz E. Is oxidative stress the pathogenic mechanism underlying insulin resistance, diabetes, and cardiovascular disease? The common soil hypothesis revisited. Arterioscler Thromb Vasc Biol. 2004;24(5):816-23.

3. Weir GC, Bonner-Weir S. Five stages of evolving betacell dysfunction during progression to diabetes. Diabetes. 2004;53(suppl 3):S16-S21.

4. Zavaroni I, Bonini L, Gasparini P, Barilli A, Zuccarelli A, Dall'Aglio E, et al. Hyperinsulinemia in a normal population as a predictor of non-insulin-dependent diabetes mellitus, hypertension, and coronary heart disease: The Barilla factory revisited. Metabolism. 1999;48(8):989-94.

5. Pollak M. Insulin and insulin-like growth factor signalling in neoplasia. Nat Rev Cancer. 2008;8(12):915-28.

6. Dankner R, Chetrit A, Shanik MH, Raz I, Roth J. Basal state hyperinsulinemia in healthy normoglycemic adults heralds dysglycemia after more than two decades of follow up. Diabetes Metab Res Rev. 2012;28(7):618-24.

7. Kraft JR. Diabetes epidemic and you. 2nd ed. Victoria, BC: Trafford; 2011.

8. Yalow RS, Berson SA. Immunoassay of endogenous plasma insulin in man. J Clin Investig. 1960;39(7).

9. Labtests. Reference Intervals 2012 [cited 2013 January 29]. Available from: http://www.labtests.co.nz/index.php?option=com_content \&view=article\&id=35: referenceintervals\&catid=26: general-information\&ltemid=157 .

10. Kraft JR. Detection of diabetes mellitus in situ (occult diabetes). Laboratory Medicine. 1975;6(2):10-22.

11. Waikato District Health Board. Laboratory test reference guide Hamilton2015 [cited 2015 September 16]. Available from: http://www.waikatodhb.govt.nz/lab/.

12. Lan-Pidhainy $\mathrm{X}$, Wolever $\mathrm{T}$. Are the glycemic and insulinemic index values of carbohydrate foods similar in healthy control, hyperinsulinemic and type 2 diabetic patients? Eur J Clin Nutr. 2011;65(6):727-34.

13. Nilsson P, Nilsson JÅ, Hedblad B, Eriksson KF, Berglund G. Hyperinsulinaemia as long-term predictor of death and ischaemic heart disease in nondiabetic men: The Malmö Preventive Project. J Intern Med. 2003;253(2):136-45.

14. Laakso M. How good a marker is insulin level for insulin resistance? Am J Epidemiol. 1993;137(9):959-65.

15. McAuley KA, Williams SM, Mann JI, Walker RJ, LewisBarned NJ, Temple LA, et al. Diagnosing insulin resistance in the general population. Diabetes Care. 2001 March 1, 2001;24(3):460-4.

16. Iwase $\mathrm{H}$, Kobayashi M, Nakajima M, Takatori T. The ratio of insulin to C-peptide can be used to make a forensic diagnosis of exogenous insulin overdosage. Forensic Sci Int. 2001;115(1-2):123-7.

17. Wilcox G. Insulin and insulin resistance. Clinical Biochemist Reviews. 2005;26(2):19-39.
18. Grunberger G, Taylor SI, Dons RF, Gorden P. Insulin receptors in normal and disease states. Clin Endocrinol Metab. 1983 Mar;12(1):191-219.

19. Schnurr TM, Reynolds AJ, Komac AM, Duffy LK, Dunlap KL. The effect of acute exercise on GLUT4 levels in peripheral blood mononuclear cells of sled dogs. Biochemistry and Biophysics Reports. 2015 7;2:45-9.

20. Farooqui AA, Farooqui T, Panza $F$, Frisardi V. Metabolic syndrome as a risk factor for neurological disorders. Cell Mol Life Sci. 2012 Mar;69(5):741-62.

21. Johnson RJ, Perez-Pozo SE, Sautin YY, Manitius J, Sanchez-Lozada LG, Feig DI, et al. Hypothesis: Could excessive fructose intake and uric acid cause type 2 diabetes? Endocr Rev. 2009;30(1):96-116.

22. Vuorinen-Markkola $\mathrm{H}$, Koivisto VA, Yki-Jarvinen $\mathrm{H}$. Mechanisms of hyperglycemia-induced insulin resistance in whole body and skeletal muscle of type I diabetic patients. Diabetes. 1992 May 1, 1992;41(5):571-80.

23. Hundal RS, Krssak M, Dufour S, Laurent D, Lebon V, Chandramouli $\mathrm{V}$, et al. Mechanism by which metformin reduces glucose production in type 2 diabetes. Diabetes. 2000 December 1, 2000;49(12):2063-9.

24. Björntorp PE, Rosmond R. Hypothalamic origin of the metabolic syndrome $x$. Ann $N$ Y Acad Sci. 1999;892(1):297-307.

25. Porte D, Baskin DG, Schwartz MW. Leptin and insulin action in the central nervous system. Nutr Rev. 2002;60:S20-S9.

26. Lustig RH, Sen S, Soberman JE, Velasquez-Mieyer PA. Obesity, leptin resistance, and the effects of insulin reduction. International Journal of Obesity \& Related Metabolic Disorders. 2004;28(10):1344-8.

27. Taylor D, Paton C, Kerwin R, editors. The Maudsley prescribing guidelines. 9th ed: Informa Healthcare; 2007.

28. Stout RW. Insulin and atheroma: 20-yr perspective. Diabetes Care. 1990 June 1, 1990;13(6):631-54.

29. Giovannucci E, Harlan DM, Archer MC, Bergenstal RM, Gapstur SM, Habel LA, et al. Diabetes and cancer: A consensus report. CA Cancer J Clin. 2010;60(4):20721.

30. Feng L, Chong MS, Lim WS, Lee TS, Collinson SL, Yap $\mathrm{P}$, et al. Metabolic syndrome and amnestic mild cognitive impairment: Singapore Longitudinal Ageing Study-2 findings. J Alzheimer's Dis. 2013;34(3):649-57.

31. Yan W, Li X. Impact of diabetes and its treatments on skeletal diseases. Front Med. 2013 Mar;7(1):81-90.

32. Mehran Arya E, Templeman Nicole M, Brigidi GS, Lim Gareth E, Chu K-Y, Hu X, et al. Hyperinsulinemia drives diet-induced obesity independently of brain insulin production. Cell Metab. 2012;16(6):723-37.

33. Monzo HJ, Park TI, Dieriks VB, Jansson D, Faull RL, Dragunow $\mathrm{M}$, et al. Insulin and IGF1 modulate turnover of polysialylated neuronal cell adhesion molecule (PSANCAM) in a process involving specific extracellular matrix components. J Neurochem. 2013;136(6):758-70. 
34. Meyer U, Feldon J, Dammann O. Schizophrenia and autism: Both shared and disorder-specific pathogenesis via perinatal inflammation? Pediatr Res. 2011;69:26R33R.

35. Kraft JR. Hyperinsulinemia: A merging history with idiopathic tinnitus, vertigo, and hearing loss. International Tinnitus Journal. 1998;4(2):127-30.

36. Fam AG. Gout, diet, and the insulin resistance syndrome. J Rheumatol. 2002;29(7):1350-5.

37. Bayir H. Reactive oxygen species. Crit Care Med. 2005;33(12):S498-S501.

38. Wiseman H, Halliwell B. Damage to DNA by reactive oxygen and nitrogen species: Role in inflammatory disease and progression to cancer. Biochem $\mathrm{J}$. 1996;313:17-29.

39. Eto K, Asada T, Arima K, Makifuchi T, Kimura H. Brain hydrogen sulfide is severely decreased in Alzheimer's disease. Biochem Biophys Res Commun. 2002 5/24/;293(5):1485-8.

40. Monnier L, Hanefeld M, Schnell O, Colette C, Owens D. Insulin and atherosclerosis: How are they related? Diabetes Metab. 2013;39(2):111-7.

41. Chilelli NC, Burlina S, Lapolla A. AGEs, rather than hyperglycemia, are responsible for microvascular complications in diabetes: A "glycoxidation-centric" point of view. Nutr Metab Cardiovasc Dis. 201323(10):913-9.

42. Stegenga ME, van der Crabben SN, Levi M, de Vos AF, Tanck MW, Sauerwein HP, et al. Hyperglycemia stimulates coagulation, whereas hyperinsulinemia impairs fibrinolysis in healthy humans. Diabetes. 2006;55(6):1807-12.

43. Olefsky JM, Farquhar JW, Reaven GM. Reappraisal of the role of insulin in hypertriglyceridemia. The American journal of medicine. 1974;57(4):551-60.

44. Vanni E, Bugianesi E, Kotronen A, De Minicis S, YkiJärvinen $H$, Svegliati-Baroni $G$. From the metabolic syndrome to NAFLD or vice versa? Dig Liver Dis. 2010;42(5):320-30.

45. Banks WA, Coon AB, Robinson SM, Moinuddin A, Shultz JM, Nakaoke R, et al. Triglycerides induce leptin resistance at the blood-brain barrier. Diabetes. 2004 May 1, 2004;53(5):1253-60.

46. Bugianesi E, McCullough AJ, Marchesini G. Insulin resistance: A metabolic pathway to chronic liver disease. Hepatology. 2005 Nov;42(5):987-1000.

47. Folsom AR, Szklo M, Stevens J, Liao F, Smith R, Eckfeldt $\mathrm{JH}$. A prospective study of coronary heart disease in relation to fasting insulin, glucose, and diabetes: The Atherosclerosis Risk in Communities (ARIC) Study. Diabetes Care. 1997;20(6):935-42.

48. Matafome P, Santos-Silva D, Sena CM, Seiça R. Common mechanisms of dysfunctional adipose tissue and obesity- related cancer. Diabetes Metab Res Rev. 2013;29(4):285-95.

49. Martin SS, Qasim A, Reilly MP. Leptin resistance: A possible interface of inflammation and metabolism in obesity-related cardiovascular disease. J Am Coll Cardiol. 2008;52(15):1201-10.
50. Henderson JR. Serum-insulin or plasma-insulin ? The Lancet. 1970;296(7672):545-7.

51. Feldman JM, Chapman BA. Radioimmunoassay of insulin in serum and plasma. Clin Chem. 1973;19(11):1250-4.

52. Wallace TM, Levy JC, Matthews DR. Use and abuse of HOMA modeling. Diabetes Care. 2004;27(6):1487-95.

53. Mather KJ, Hunt AE, Steinberg HO, Paradisi G, Hook $G$, Katz A, et al. Repeatability characteristics of simple indices of insulin resistance: Implications for research applications. The Journal of Clinical Endocrinology \& Metabolism. 2001;86(11):5457-64.

54. Samaras K, McElduff A, Twigg SM, Proietto J, Prins JB, Welborn TA, et al. Insulin levels in insulin resistance: Phantom of the metabolic opera? Med J Aust. 2006;185(3):159.

55. Samaras K, McElduff A, Twigg SM, Proietto J, Prins JB, Welborn TA, et al. Insulin levels in insulin resistance: Phantom of the metabolic opera? Med J Aust. 2006;185(3):159.

56. Mari A, Pacini G, Murphy E, Ludvik B, Nolan J. A model-based method for assessing insulin sensitivity from the oral glucose tolerance test. Diabetes Care. 2001;24(3):539-48.

57. Tam CS, Xie W, Johnson WD, Cefalu WT, Redman LM, Ravussin E. Defining insulin resistance from hyperinsulinemic-euglycemic clamps Diabetes Care. 2012 July 1, 2012;35(7):1605-10.

58. Diamond MP, Thornton K, Connolly-Diamond M, Sherwin RS, DeFronzo RA. Reciprocal variations in insulin-stimulated glucose uptake and pancreatic insulin secretion in women with normal glucose tolerance. J Soc Gynecol Investig. 1995;2(5):708-15.

59. Katz A, Nambi SS, Mather K, Baron AD, Follmann DA, Sullivan $G$, et al. Quantitative insulin sensitivity check index: A simple, accurate method for assessing insulin sensitivity in humans. Journal of Clinical Endocrinology \& Metabolism. 2000 July 1, 2000;85(7):2402-10.

60. World Health Organization. Definition, diagnosis and classification of diabetes mellitus and its complications. Geneva: World Health Organization, 1999.

61. Schmiegelow MD, Hedlin H, Stefanick ML, Mackey RH, Allison M, Martin LW, et al. Insulin resistance and risk of cardiovascular disease in postmenopausal women: A cohort study from the Women's Health Initiative. Circulation: Cardiovascular Quality and Outcomes. 2015 May 1, 2015;8(3):309-16.

62. Hayashi T, Boyko EJ, Sato KK, McNeely MJ, Leonetti $\mathrm{DL}$, Kahn SE, et al. Patterns of insulin concentration during the OGTT predict the risk of type 2 diabetes in Japanese Americans. Diabetes Care. 2013;36(5):122935.

63. Huxley R, Barzi F, Woodward M. Excess risk of fatal coronary heart disease associated with diabetes in men and women: Meta-analysis of 37 prospective cohort studies. BMJ. 2006;332(7533):73-8.

64. Donnelly R, Emslie-Smith AM, Gardner ID, Morris AD. $A B C$ of arterial and venous disease: Vascular complications of diabetes. BMJ. 2000;320(7241):1062. 
65. Maisch B, Alter P, Pankuweit S. Diabetic cardiomyopathy--fact or fiction? Herz. 2011;36(2):10215.

66. Tarquini R, Lazzeri C, Pala L, Rotella CM, Gensini GF. The diabetic cardiomyopathy. Acta Diabetol. 2011;48(3):173-81.

67. Rask-Madsen C, King GL. Mechanisms of disease: Endothelial dysfunction in insulin resistance and diabetes. Nature Clinical Practice Endocrinology \& Metabolism. 2007;3(1):46-56.

68. Kaaja R, Rönnemaa T. Gestational diabetes: Pathogenesis and consequences to mother and offspring. The review of diabetic studies: RDS. 2008;5(4):194.

69. Flores-Riveros JR, McLenithan JC, Ezaki O, Lane MD. Insulin down-regulates expression of the insulinresponsive glucose transporter (GLUT4) gene: effects on transcription and mRNA turnover. Proceedings of the National Academy of Sciences. 1993;90(2):512-6.

70. Scheepers A, Joost $H$, Schurmann A. The glucose transporter families SGLT and GLUT: molecular basis of normal and aberrant function. J Parenter Enteral Nutr. 2004 September 1, 2004;28(5):364-71.

71. Medina-Santillán R, López-Velázquez JA, Chávez-Tapia $N$, Torres-Villalobos $G$, Uribe $M$, Méndez-Sánchez $N$. Hepatic manifestations of metabolic syndrome. Diabetes Metab Res Rev. 2013.

72. Marchesini G, Brizi M, Morselli-Labate AM, Bianchi G, Bugianesi E, McCullough AJ, et al. Association of nonalcoholic fatty liver disease with insulin resistance. The American journal of medicine. 1999;107(5):450-5.

73. Marques-Vidal $P$, Bastardot $F$, Känel $R$, Paccaud $F$, Preisig M, Waeber $G$, et al. Association between circulating cytokine levels, diabetes and insulin resistance in a population-based sample (CoLaus study). Clin Endocrinol (Oxf). 2013;78(2):232-41.

74. Choi SM, Tucker DF, Gross DN, Easton RM, DiPilato LM, Dean AS, et al. Insulin regulates adipocyte lipolysis via an Akt-independent signaling pathway. Mol Cell Biol. 2010 November 1, 2010;30(21):5009-20.

75. Swinburn BA, Sacks G, Lo SK, Westerterp KR, Rush $E C$, Rosenbaum $M$, et al. Estimating the changes in energy flux that characterize the rise in obesity prevalence. Am J Clin Nutr. 2009;89(6):1723-8.
76. Yu JH, Shin MS, Kim DJ, Lee JR, Yoon SY, Kim SG, et al. Enhanced carbohydrate craving in patients with poorly controlled Type 2 diabetes mellitus. Diabetic Medicine. 2013;30(9):1080-6.

77. Humpel C. Chronic mild cerebrovascular dysfunction as a cause for Alzheimer's disease? Exp Gerontol. 2011;46(4):225-32.

78. Razay G, Wilcock G. Hyperinsulinaemia and Alzheimer's disease. Age Ageing. 1994;23:396-9.

79. Erol A. An integrated and unifying hypothesis for the metabolic basis of sporadic Alzheimer's. Journal of Alzheimer's Disease. 2008;13:241-53.

80. Barkhof F, Fox NC, Bastos-Leite AJ, Scheltens P. Vascular dementia. Neuroimaging in Dementia. Berlin: Springer; 2011. p. 137-76.

81. Qiu WQ, Folstein MF. Insulin, insulin-degrading enzyme and amyloid- beta peptide in Alzheimer's disease: Review and hypothesis. Neurobiology of Aging. 2006;27(2):190-8.

82. Sadosky A, Schaefer C, Mann R, Bergstrom F, Baik R, Parsons $B$, et al. Burden of illness associated with painful diabetic peripheral neuropathy among adults seeking treatment in the US: results from a retrospective chart review and cross-sectional survey. Diabetes, metabolic syndrome and obesity: targets and therapy. 2013;6:79.

83. Kim B, McLean LL, Philip SS, Feldman EL. Hyperinsulinemia induces insulin resistance in dorsal root ganglion neurons. Endocrinology 2011;152(10):3638-47.

84. Poulaki V, Qin W, Joussen AM, Hurlbut P, Wiegand SJ, Rudge $J$, et al. Acute intensive insulin therapy exacerbates diabetic blood-retinal barrier breakdown via hypoxia-inducible factor-1 betaand VEGF. J Clin Investig. 2002;109(6):805-15.

85. Kang D-H, Kanellis J, Hugo C, Truong L, Anderson S, Kerjaschki D, et al. Role of the microvascular endothelium in progressive renal disease. J Am Soc Nephrol. 2002 March 1, 2002;13(3):806-16.

86. Hamer RA, EI Nahas AM. The burden of chronic kidney disease: Is rising rapidly worldwide. BMJ. 2006;332(7541):563.

87. Forbes JM, Coughlan MT, Cooper ME. Oxidative stress as a major culprit in kidney disease in diabetes. Diabetes. 2008 June 1, 2008;57(6):1446-54. 